Pero la aportación del autor no se limita a una mera descripción de resultados, por otro lado muy minuciosa y completa, sino que desarrolla una interpretación en clave histórica que relaciona los datos obtenidos con las técnicas de otras escuelas europeas y con la información de los tratados de los siglos XVII y XVIII. La contribución de Rafael Romero es una excelente oportunidad no solo para conocer una interesantísima documentación técnica gracias a la magnífica reproducción de las imágenes y al trabajo de conexión de datos facilitado por el autor; también nos permite dirigir una mirada de conjunto a través de su personal análisis sobre este género pictórico tan poco estudiado desde el punto de vista técnico.

Su trabajo se identifica, pues, con este nuevo campo de conocimiento que habitualmente llamamos "estudios técnicos de obras de arte" y que, como indica el autor en la introducción, en el mundo anglosajón se ha acuñado como technical art history, un campo que resulta cada vez más indispensable para complementar los enfoques tradicionales de la historia del arte. Confiamos que la labor emprendida por Rafael Romero se vea continuada por sucesivas investigaciones y publicaciones que enriquezcan este campo de estudio de la pintura española.

Rocío Bruquetas

Instituto del Patrimonio Cultural de España

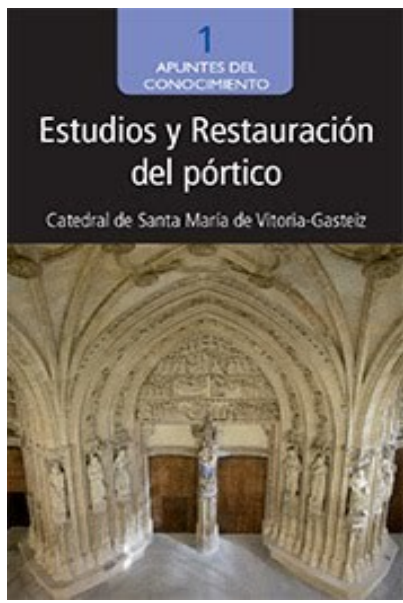

\title{
Estudios y Restauración del pórtico. Catedral de Santa María de Vitoria-Gasteiz
}

\author{
Mercedes Cortazar, Diana Pardo y Dolores Sanz
}

Edita: Santa Maria Katedrala Fundazioa - Fundación Catedral Santa María

Colección «Apuntes del Conocimiento»

Vitoria - Gasteiz, 2009

291 páginas, ilustraciones, gráficos, figuras, $24 \times 17 \mathrm{~cm}$.

ISBN : 978-84-613-5473-3

El ejemplo de la Restauración de la Catedral de Santa María de Vitoria-Gasteiz es hoy conocido por casi todos los especialistas en Conservación-Restauación de monumentos. Se ha convertido en un ejemplo y referente obligado por su enfoque metodológico, dentro de los planes directores de catedrales, y por su repercusión en la afluencia de turismo cultural, "turismo del conocimiento" como les gusta decir a los responsables de la Fundación Catedral Santa María, que ayuda a la sostenibilidad y al desarrollo del casco histórico de la ciudad de Vitoria-Gasteiz. Tanto es así que su programa de visitas "abierto por obras" ha sido imitado en otros muchos proyectos de intervención, en España y en el extranjero, aunque con diferente fortuna.

Es precisamente de esta filosofía de "restauración abierta", que surge como consecuencia de un convencimiento profundo de la función social del Patrimonio y de la necesidad de "socializar el conocimiento", de devolver a la sociedad la información y los conocimientos que se van desprendiendo de los múltiples trabajos, investigaciones y estudios interdisciplinares que se están llevando a cabo en la Catedral de Santa María, mediante una amplia labor de divulgación con visitas guiadas, conferencias, página Web de la Fundación Catedral Santa María, de la que nace también la 
colección "Apuntes del Conocimiento", con un enfoque más científico y por lo tanto dirigido a un público especializado, cuyo primer número está dedicado al texto que ahora comentamos: Estudios y Restauración del pórtico. Catedral de Santa María de Vitoria-Gastei\%.

El libro es el fruto de la labor de estudio e intervención dirigido por las autoras y que se llevó a cabo durante tres años, junto con un nutrido equipo de especialistas en Restauración, con la colaboración de otros especialistas en Historia del Arte, Arqueología, Química.

Tras una muy breve introducción, con aclaraciones sobre la documentación previa, elaboración de bases de datos específicas, etc., se desarrolla el primer capítulo importante, dedicado a la Metodología. En él se describen los estudios previos realizados, cuya finalidad era "conocer con exactitud la composición, material, extensión y conservación de la policromía original y de cada una e las capas a ella superpuestas, y después establecer una correspondencia entre todos los elementos estudiados y asi conocer su evolución polícroma a través de los siglos", como base para la elaboración de una propuesta de intervención adecuada. El trabajo ha consistido fundamentalmente en la aplicación de la técnica de estudio de "correspondencia de policromías". Por ello, en este apartado, se enumeran las distintas fases del mismo: examen preliminar, examen al microscopio de los puntos de estudio seleccionados, documentación gráfica y fotográfica de los mismos, toma de muestras y exámenes de laboratorio, elaboración de la carta de correspondencia y reconstrucción gráfica de las policromías, que se compaginan y completan con trabajos de urgencia y pruebas de tratamiento, antes de la elaboración de conclusiones y propuesta de intervención.

Basándose en su larga trayectoria profesional y en experiencias previas, como el estudio del pórtico Este de la iglesia de San Pedro, también en Vitoria, establecen los criterios de aplicación de esta técnica a un conjunto tan grande y complejo como el de este pórtico, con la realización de fichas de campo y su traslación a bases de datos, la necesidad de establecer criterios y estrategias de distribución del trabajo en grupo, la definición de códigos de interpretación uniformes para ser usados por todos los miembros del equipo, la organización del orden de los recorridos y las fases de estudio, etc. Una labor de logística y coordinación que pasa desapercibida dentro del texto y que sin embargo supone una de las aportaciones metodológicas más interesantes de este complejo trabajo.

El tercer capítulo, se dedica a desarrollar la parte documental y el estudio histórico e históricoartístico, necesario para relacionar las evidencias materiales y documentales y poder establecer, partiendo de unas cronologías relativas derivadas de la superposición estratigráfica, las cronologías absolutas, contrastadas con datos documentales y estilísticos.

El cuarto capítulo se centra en la descripción técnica de los diferentes elementos estudiados: el soporte de piedra, su labrado, los materiales, técnicas y utillaje con los que fueron realizados, etc.; los morteros, su tipología y composición; los pigmentos usados en las decoraciones y las diferentes técnicas empleadas por los pintores (temples, óleo o pintura a la cal).

El quinto capítulo desarrolla las conclusiones extraídas del estudio de correspondencia de policromías. Hace una enumeración de las diferentes fases polícromas del pórtico desde el siglo XIV hasta el XX, quince en total, deteniéndose especialmente en las nueve fases del parteluz. Incluye también la reconstrucción de las policromías de numerosos elementos, como la Capilla de los Paternina o las distintas bóvedas y claves en tres momentos concretos (siglo XVI, XVIII y

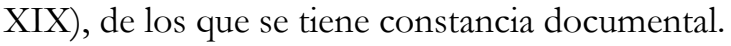

Los capítulos sexto y séptimo se dedican a la descripción del estado de conservación de las diferentes zonas de estudio: bóvedas e intradoses, portadas, parteluz, cabecera y muros fronteros y a los tratamientos realizados con una filosofía de mínima intervención. Finalmente se dedica un capítulo a la propuesta de modelo de pliego de prescripciones técnicas para casos similares, 
derivado de la experiencia de los trabajos realizados. Teniendo en cuenta que, en este proyecto, a la fase de estudios previos se le dedicó año y medio de trabajo (la misma cantidad de tiempo que a la realización de los trabajos de restauración propiamente dichos), estamos ante un caso poco habitual. Esto de por sí representa un enfoque metodológico novedoso, que ejemplifica la importancia de la fase de investigación previa para una correcta toma de decisiones y la elaboración de una propuesta de intervención y un pliego de prescripciones técnicas adaptado a las necesidades reales de cada caso.

Si hubiera que mencionar algún aspecto negativo del presente texto, sería la normalidad con la que se describen los resultados de un estudio tan excepcional, la poca importancia que se da a la labor realizada y a los esfuerzos técnicos y logísticos, que si se hubiese presentado en un ámbito diferente, universitario o investigador, obviamente se habrían resaltado más.

Emilio Ruiz de Arcaute Martínez Servicio de Restauración de la Diputación Foral de Álava

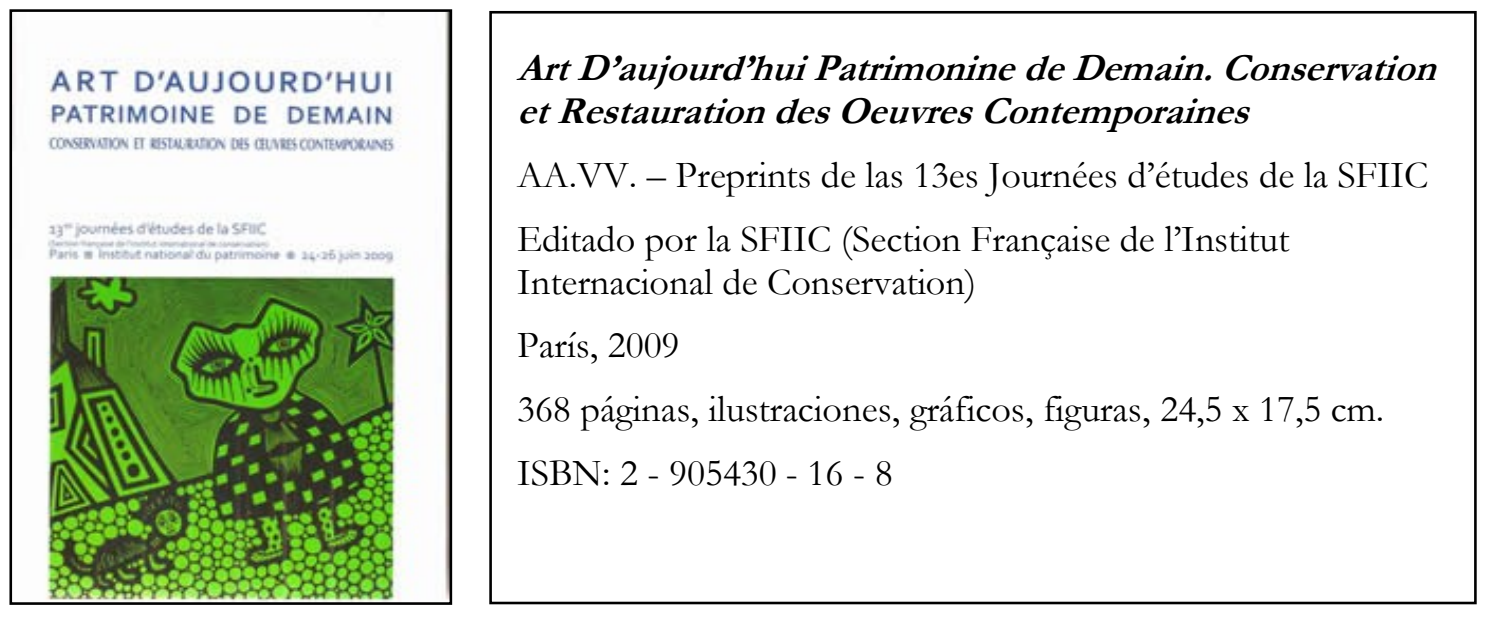

La Sección Francesa del Internacional Institut of Conservation (SFIIC) lleva muchos años realizando congresos, simposios o jornadas y publicando textos de referencia en Francia (Patrimoine cultural et altérations biologiques, Les anciennes restaurations en peinture murale", "La conservation des textiles anciens, L'album photographique, conservation et histoire d'un objet, Retables in situ - conservation \& restauration, etc.). Los eventos organizados por la SFIIC suelen tener un carácter monotemático e internacional, buscando como resultado la presentación de un "estado de la cuestión" sobre el tema tratado, como ha ocurrido en este caso.

El libro incluye los trabajos presentados en las 13es Journées d'études de la SFIIC, que tuvieron lugar en París, durante los días 24, 25 y 26 de junio de 2009, dedicadas a estudiar los problemas específicos del arte contemporáneo. Las 39 comunicaciones, que aparecen publicadas en el idioma de su presentación (inglés o francés), con un resumen en la otra lengua, están organizadas en base a seis ítems principales: - Derecho, ética y deontología, - Instalaciones y móviles, - Materiales sintéticos, - Pintura y artes gráficas, - Fotografía y nuevos medios y, por último, - Arte monumental y al aire libre. El texto concluye con un capítulo de pósteres, 24 en total. 